\title{
DOGVILLE: um conto urbano
}

\author{
Astrid Tirel ${ }^{*}$
}

\section{Aspectos contextuais}

Nós achamos, como Marc Le Bot (1991), que o pensamento artístico é determinante no equilíbrio de uma sociedade. Pelo ato criador, o artista procura sair do contexto, das instituições, da história que ele mesmo ajudou a instaurar. Sendo assim sua criação interroga, revoluciona, questiona os valores da sociedade. O cinema participa na renovação do pensamento das sociedades propondo produções nas quais as implicações vão além das questões estéticas atribuídas ao espetáculo para interrogar os atores sociais.

O espetáculo não é só um conjunto de imagens, mas uma relação entre pessoas, mediatizada por imagens. (Debord, 1992, p. 4)

É por essa reflexão de Guy Debord que nós vamos nos interessar pelo filme do cineasta dinamarquês Lars Von Trier, Dogville (Trier, 2002). Palma de Ouro no Festival de Cannes em 2003, o filme provocou muitos debates, interrogando ao mesmo tempo o seu dispositivo cênico e a sua dramaturgia ao serviço de uma severa crítica da sociedade. Lars Von Trier posicionou essa cidade nos EUA.

Eu queria realizar esse filme nos Estados Unidos, situá-lo nesse país aonde eu nunca fui. Isso não tem nada a ver com os Estados Unidos, são somente os sentimentos que eu tenho sobre o país. Eu me sinto como um americano (Inch bin ein American!). (Trier, 2003)

Essa escolha geográfica pode ser interpretada como uma provocação destinada a entreter uma imagem mediática já controvertida. No entanto, esses propósitos podem também traduzir uma interrogação sobre o futuro de nossas sociedades. Em verdade,

Departamento de Sociologia, Université de Québec à Montreal (UQAM).

Tradução: Lucas Henri Girard F. Nunes. 
no contexto atual de mundialização (expansão das trocas internacionais, fluxos migratórios de pessoas e bens), as sociedades dominadas pela lógica mercantil parecem convergir para um tipo de sociedade única, onde a industrialização massiva teria tendência a apagar as diferenças. Aqui, Jean-Charles Lagrée junta-se às interrogações de Lars Von Trier quando ele acusa:

A homogeneização, a uniformização, a perda da identidade e de referências, a americanização, o controle da diversidade mundial (...). O que dá medo é que os particularismos dos vilarejos do planeta desapareçam e que, ao invés, se construa um mundo uniforme a partir do modelo de eficácia racional a serviço do mercado (Lagrée, 2000, p. 20, 21)

Também, se "Inch bin ein American" só pode relembrar que nós "somos todos americanos" pontuados pela imprensa e pela abordagem política mundial desde os acontecimentos do 11 de setembro 2001, pode também traduzir um sentimento de indiferenciação entre uma cidade da América do Norte e outra, qualquer que seja a sua localização geográfica, toda cidade podendo ser então americana. É nessa perspectiva de uma cidade urbana, situada em um sem-lugar e apresentando características comuns a muitas outras cidades, que o cineasta mostra a sua arte.

\section{O autor}

Lars Von Trier é um cineasta europeu reconhecido no mundo do cinema onde faz papel de inovador. Sua contribuição à vanguarda cinematográfica - ou ao menos a uma tentativa de renovação do gênero - se inscreve num movimento visando reconsiderar a ética cinematográfica. Com mais três outros cineastas, ele escreveu um manifesto, o Dogma 95, composto de 10 regras que os signatários “juram” aplicar nas suas práticas cinematográficas. Essas regras são limites técnicos e ideológicos que cruzam o mundo do cinema tanto do ponto de vista estético quanto econômico e político. Em um plano mais pragmático, a abordagem do Dogma se aproxima da de Jerzy Grotowski (para o teatro), e que dá preferência a um cinema pobre 
(sem efeitos especiais) que botaria o trabalho do ator no coração do dispositivo. Os filmes criados sobre esse modelo fizeram sucesso.

Mas o Dogma faz com que o cineasta seja impopular, porque suas escolhas cinematográficas não são sempre conformes (quando não são completamente opostas) aos preceitos que ele se engajou a respeitar no seu "voto de castidade". Duvidamos então de sua integridade e suspeitamos uma operação de marketing mediatizada. Do mais, a sua concepção de cinema ameaça os técnicos e os realizadores dos quais as práticas participam desse cinema de "ilusão" criticado pelos membros do Dogma. Também alguns se associaram para criar um anti-dogma que se opõe em todos os aspectos ao Dogma 95.

O que nos importa aqui não é tanto o caráter polêmico dos atos do cineasta, atos que nós consideramos sobre tudo em coerência com um status de artista, no qual seu papel se interessa em transgredir as fronteiras (Heinrich, 1998). O que nos interessa se situa na dialética que se usa entre os questionamentos de caráter internacional contidos em um filme como Dogville e a profunda implicação do cineasta no seio de um sistema que ele ataca. Essa postura impossível traduziria um mal-estar constitutivo de nossas escolhas de sociedade?

\section{A cidade}

Dogville, que nós poderíamos traduzir em português por "cidade de cachorro", está descrita como isolada, situada nas Montanhas Rochosas. O nome dado a esta cidade prediz o pouco de simpatia que lhe é atribuída. Associada a um animal, todo o caráter humano parece ter sido recusado. A cidade não é nem policêntrica nem monocêntrica, mas periférica e situada em uma terra de ninguém parecendo suspensa em um vazio econômico (Davezies, 2000). Dogville não tem representante religioso, nem escola, nem prefeitura. Todas as suas instituições são ausentes. Somente as instituições repressivas tocam a comuna. Assim, uma prisão foi construída não muito longe, e um representante da lei passa de tempos em tempos para informar os habitantes a respeito de notícias sobre a criminalidade. 
O narrador apresenta cidade nesses termos:

A comuna repousava em uma espécie de plataforma moldada pelos detritos da exploração mineira agora silenciosa. Canyon Road saía na Elm Street, com suas oito ou dez habitações, para acabar onde a ladeira ficava abrupta, bem perto da entrada da velha mina de prata abandonada. (Dogville, 2004)

Pela sua descrição pouco elogiosa, imaginamos a cidade com uma antiga prosperidade, enquanto sua população pouco numerosa testemunha a sua pouca atividade atual. Dessa maneira a cidade é apresentada como a razão de ser e a resultante de uma atividade que não mais existe. Nesse sentido ela é um produto da sociedade (Weber, 2001). De fato, Dogville tem somente uma loja, onde se vendem coisas inúteis a um custo muito elevado para a clientela da cidade.

O cineasta situa Dogville nos anos 30 nos EUA. Nessa época, a bolsa de Nova York despenca (1929). A crise econômica afeta todo o comércio internacional e provoca uma importante crise social (desemprego). $\mathrm{O}$ aspecto austero da cidade contrasta com as inúmeras atividades que antes prosperavam nesse local, a mina de prata, símbolo de abundância e de explorações industriais e a paisagem participam também na idéia de uma cidade fundada sobre um projeto comerciante. É uma paisagem única na qual os espaços públicos (ruas) e privados (casas) são delimitados por um traço de giz branco sobre um palco preto, trazendo o aspecto da cidade a um projeto urbanístico, a uma então planificação. A crise generalizada provoca uma interiorização em si mesmo, o medo do outro e a subida de nacionalismos (Mussolini na Itália, Hitler na Alemanha).

Lars Von Trier nos propõe mergulhar nessa representação miniatura da sociedade guardando uma visão distanciada, mais própria à observação. Pour se faire, et par une mise em scène austère et épuree, o espectador penetra na cidade guiado por um plano vertical descendente, efetuado por uma câmera situada sobre a cena. Também várias vezes o personagem descreve a situação como uma "ilustração", relembrando assim que o cineasta propõe uma experimentação. Mas o que se passa em Dogville? 


\section{Os protagonistas}

Nós focalizaremos somente dois personagens-chave do conto, tendo em vista o propósito que queremos demonstrar. Faremos referências aos outros personagens somente pelo intermediário do grupo que eles formam, os habitantes.

Grace, bela fugitiva, acha o seu refúgio em Dogville, onde um aspirante escritor, Tom Edison, lhe faz uma estranha oferta. Para ficar na cidade, Grace tem duas semanas para se fazer gostar pelos habitantes. Ajudando-os nas suas tarefas diárias, a jovem mulher não tarda a ser indispensável para o bem-estar de todos. Porém, ao saberem que Grace era, de fato, perigosa, as boas almas de Dogville se corrompem e mudam de atitude para com ela, até abusar dela sem escrúpulos. (Voir, 2004)

\section{A figura do estrangeiro}

Grace, cujo nome sugere ao mesmo tempo inocência e beleza, é o personagem central e o papel pivô desse conto urbano. Por ela chega a mudança e também toda a intriga do filme se constrói em volta desse personagem. É a figura do estrangeiro na cidade. Ela não tem ligações (orgânicas) com a cidade; é uma viajante em potencial. Ninguém conhece a duração de sua estadia na cidade, nem mesmo ela. Para Simmel (1908) o acolhimento a um estrangeiro permite medir o tamanho da coesão social de um grupo, procurando as similitudes e/ou as diferenças. A procura das similitudes interroga os valores universalistas, e a primeira das similitudes traz a humanidade comum. Também o princípio universalista convida a uma aproximação moral da questão. Grace, inicialmente, é acolhida pelos habitantes sobre a base de sua humanidade comum. Mas eles não desejam integrá-la em seu cotidiano, sendo que nenhuma tarefa da qual ela poderia ser dispensada lhes parece dispensável. Mas, o princípio da coabitação sendo a troca, sua integração ao grupo é condicionada a algo que ela possa dar. Do mais, para que essa ligação contratual tome forma e dure, é preciso um mediador. 


\section{O mediador}

Thomas Edison, escritor em desenvolvimento, é, como o seu nome deixa presumir, o mediador desse conto urbano.Thomas Edison queria trazer algo para sua comunidade, ele se sente envolvido e responsável por ela. Mas ele não queria contar algo que se passava somente "na cidade", mas "algo universal". Lars Von Trier se exprime através de Thomas Edison, e nos dá as condições de sua experimentação: conceber a cidade como um laboratório social (Park, 1929) que algo trazido do exterior poderia fazer reviver. Ele acha que a chegada da estrangeira é um dom e se propõe a fazer uma ilustração. Além do mais, assumindo o papel de prefeito em potencial, ele se encarrega de fixar os termos das trocas entre a estrangeira e os habitantes da cidade, deixando-os perceber a oportunidade de provar a existência de sua comunidade através de um ato comum. Em troca de sua presença e de sua proteção, Grace trabalhará cada dia em uma residência.

Nós vimos que Dogville não tem instituições de serviços habitualmente representados nas cidades. Grace oferece os seus serviços à comunidade ajudando uma menina deficiente, conversando com um homem cego e só, ajudando na colheita da maçã, cuidando das crianças e ensinando-as, jardinando, cozinhando, cercando de cuidados o médico aposentado do vilarejo, arrumando o órgão da igreja, etc. A estrangeira faz parte do grupo sem realmente fazer parte dele. Como cada habitante da comunidade, ela tem um lugar pra morar. Ela está livre para ir embora (porém sem nenhum lugar pra ir) e ligada a essa comunidade, da qual ela recolhe as confidências individuais, o que lhe confere um papel estratégico na dinâmica do grupo. Sua atividade é agora vista como indispensável e reconstitui o ligamento social da comunidade.

\section{A exclusão}

A ameaça exterior torna-se presente e os habitantes estão inquietos. Ainda que Dogville esteja longe dos fluxos de atividade 
de outras cidades, ela não vive em completo isolamento. E as repetidas visitas do representante da lei convida os habitantes a assumir o tamanho de seus engajamentos: protegendo uma mulher procurada pelas autoridades, eles estão fora da lei e, quem sabe, em perigo.

Então, os termos das trocas são rompidos por duas vezes. A primeira ruptura acontece quando as representações dos habitantes da cidade para com a estrangeira mudam, modificando substancialmente as atitudes em relação a ela. A estrangeira deve multiplicar o seu tempo de trabalho para compensar o risco que ela faz os habitantes da comunidade correr. Nenhuma retribuição lhe é dada em troca. Potencialmente perigosa, a estrangeira torna-se um problema para a comunidade. Paradoxalmente, os habitantes têm cada vez menos confiança nela, contudo eles a inserem nas suas vidas privadas cada vez mais. Parece que a figura do estrangeiro faz parte integrante do processo de identificação dos habitantes de Dogville ao nível de grupo. Ela é a alteridade que autoriza a similitude e, nesse sentido, ela parece condenada a ser sempre uma estrangeira.

Além disso, a representação dos habitantes como alteridade resiste na concepção de Grace, já que lhe sobra o mediador. Ela também não é totalmente excluída da cidade. A relação com esse personagem permanecendo estável, a sua ligação com a alteridade se mantém, o que lhe permite manter sua "auto-estima" mesmo sendo explorada, amarrada e abusada sexualmente.

A segunda ruptura traz uma mudança com tamanha conseqüência que a estrangeira não tem mais o seu lugar na comunidade. Ela não tem mais mediador. A presença da estrangeira permitiu à cidade consolidar sua ligação social reconstituindo a sua identidade diante da alteridade que a jovem representava. Efetivamente, Thomas Edison se aproxima dos habitantes da cidade que, não entendendo a sua teimosia em defender Grace, se preparavam para excluí-lo do grupo. A ilustração não tem mais razão de ser. A estrangeira agora perdeu seu papel estratégico diante dos habitantes da cidade e seu mediador de uma vez. Unidos como um só homem, os habitantes condenam Grace entregando-a aos gângsteres que a perseguiam. Ao mesmo tempo, Dogville se prepara para acolher a 
nova figura de estrangeiro com o qual o comércio se anuncia mais promissor.

A união dos habitantes cria ao mesmo tempo a sua perda. Pensando entregar Grace aos gângsteres, eles a aproximam de seu pai e reconstituem assim suas próprias ligações. Uma solidariedade mecânica está então diante de uma solidariedade orgânica. Nesse conto, a primeira terá razão sobre a primeira.

Depois desta reflexão, convicta, Grace conclui que "o mundo seria melhor sem essa cidade" e todos os habitantes são executados.

\section{Conclusão}

Com esse conto urbano, Lars Von Trier se interroga sobre o lugar do estrangeiro na cidade. Assim sendo, ele interroga as relações que se fazem entre os seres no interior de um sistema fechado como a cidade. Efetivamente a urbanidade se caracteriza por uma certa liberdade e por uma rede de informações que lhe dão vida e sentido, a sua existência apresenta algum interesse se os habitantes que a criam se mostram incapazes de coabitar? Através desse estudo da cidade, o cineasta Alain Touraine (1997) se questiona sobre nossa capacidade de viver viver juntos, sendo iguais e diferentes.

Sua crítica exagerada do americanismo generalizado levanta a questão das fronteiras, as que nós levantamos individualmente e coletivamente ao mesmo tempo nos nossos espaços privados, como o espírito, e nos espaços públicos, como nossas cidades. E se a cidade é caracterizada somente por nossas instituições repressivas, sobrará um lugar para exercer nossa sociabilidade?

Mas, se a cidade é o mundo que o homem criou, é também o mundo que ele se condenou a viver (Park,1929, p. 67). 


\section{Referências bibliográficas}

DAVEZY, Laurent. La ville des économistes. In: Parquot, T.; Lussault, M.; Bodygendrot, S. (Org.). La ville et l'urbain: l'etat des savoirs. Paris: La Decouverte, 2000.

DEBORD, Guy. La société du spectacle. Paris: Gallimard, 1992.

DOGVILLE. Site oficial do filme: <http://www.dogvillemovie.com/> .

DOGME. Tradução francesa, disponível em: <http://www.thothfiction.com/ dogme.htm>.

HEINICH, Nathalie. Le triple jeu de l'art contemporain. Paris: Les Editions de Minuit, 1998.

LE BOT, Marc. Pensée artistique et expérience de l'altérité. Esprit, L'art aujourd'hui, n. 173, juillet-août, 1991.

SIMMEL, George. Digressions sur l'étranger (1908). In: Grafmeyer, T.; Joseph, I. (Ed.). L'école de Chicago: naissance de l'écologie urbaine. Cidade??: Edition du Champ Urbain, 1979. p. 53-59.

TOURAINE, Alain. Pourrons-nous vivre ensemble? Egaux et différents. Paris: Fayard, 1997.

VOIR, hebdomadaire du 3 au 9 juin 2009, v. 18, n. 22, p. 55.

WEBER, Max. La ville. Paris: Aubier, 2001.

\section{Anexo}

\section{"Votos de castidade" do Dogma 95 fundado por Lars Von Trier}

$\mathrm{Eu}$ juro submeter-me às regras seguintes, estabelecidas e confirmadas pelo Dogma 95:

$\S$ A filmagem deve ser feita exteriormente. Acessórios e decoração não podem ser fornecidos (se um acessório é necessário para a história, deve-se escolher um dos exteriores onde se encontra esse acessório).

$\S$ O som nunca deve ser produzido separadamente das imagens e vice-versa (não deve-se usar música, a menos que ela esteja presente aonde a cena está sendo rodada). 
§ A câmera deve ser segurada no ombro. Todo movimento ou imobilidade - feito no ombro está autorizado. (É a filmagem que deve ser feita aonde o filme é feito).

$\S$ O filme deve ser a cores. A luminosidade especial não é aceitável. (Se há pouca luz, a cena deve ser cortada, ou então deve-se montar somente uma lâmpada na câmera).

$\S$ Truques e filtros estão proibidos.

$\S$ O filme não deve conter nenhuma ação superficial (assassinatos, armas, etc. em nenhum caso).

$\S$ As alienações temporais e geográficas estão proibidas (quer dizer que o filme acontece aqui e agora).

$\S$ Os filmes de gênero são inaceitáveis.

$\S$ O formato do filme deve ser em $35 \mathrm{~mm}$ standard.

$\S$ O cineasta não deve ser credenciado.

Além disso, eu juro, como cineasta, de me abster de todo gosto pessoal! Não sou mais um artista. Eu juro abster-me de criar "uma obra", porque eu considero que o instante é mais importante que a totalidade. Meu objetivo supremo é forçar a verdade sair dos meus personagens e sair do contexto da ação. Eu juro fazê-lo por todos os meios disponíveis fora de qualquer bom-gosto e de qualquer consideração estética. Assim, eu pronuncio meu voto de castidade. 